\title{
Effect of HF Concentration on Physical and Electronic Properties of Electrochemically Formed Nanoporous Silicon
}

\author{
Pushpendra Kumar, ${ }^{1}$ Peter Lemmens, ${ }^{1}$ Manash Ghosh, ${ }^{1}$ Frank Ludwig, ${ }^{2}$ \\ and Meinhard Schilling ${ }^{2}$ \\ ${ }^{1}$ Physik der Kondensierten Materie, TU Braunschweig, 38106 Braunschweig, Germany
${ }^{2}$ Institut für Elektrische Messtechnik und Grundlagen der Elektrotechnik, TU Braunschweig, 38106 Braunschweig, Germany \\ Correspondence should be addressed to Pushpendra Kumar, p.kumar@tu-bs.de
}

Received 8 June 2008; Revised 28 August 2008; Accepted 8 January 2009

Recommended by Rakesh Joshi

The most common fabrication technique of porous silicon (PS) is electrochemical etching of a crystalline silicon wafer in a hydrofluoric (HF) acid-based solution. The electrochemical process allows for precise control of the properties of PS such as thickness of the porous layer, porosity, and average pore diameter. The effect of HF concentration in the used electrolyte on physical and electronic properties of PS was studied by visual color observation, measuring nitrogen sorption isotherm, field emission type scanning electron microscopy, Raman spectroscopy, and photoluminescence spectroscopy. It was found that with decrease in HF concentration, the pore diameter increased. The PS sample with large pore diameter, that is, smaller nanocrystalline size of Si between the pores, was found to lead to a pronounced photoluminescence peak. The systematic rise of photoluminescence peak with increase of pore diameter and porosity of PS was attributed to quantum confinement. The changes in nanocrystalline porous silicon were also clearly observed by an asymmetric broadening and shift of the optical silicon phonons in Raman spectra. The change in electronic properties of PS with pore diameter suggests possibilities of use of PS material as a template for fundamental physics as well as an optical material for technological applications.

Copyright (C) 2009 Pushpendra Kumar et al. This is an open access article distributed under the Creative Commons Attribution License, which permits unrestricted use, distribution, and reproduction in any medium, provided the original work is properly cited.

\section{Introduction}

Porous silicon (PS) has attracted great interest both from fundamental physics [1-3] point of view as well as its technological applications in biological and chemical sensors, light emitting diodes, microdevices, and photoelectric solar batteries [4-8]. The PS can be prepared by the electrochemical anodization etching technique [9], stain etching processes [2] in a hydrofluoric acid-based solution, and a hydrothermal etching technique [10] in a hydrofluoric acid free solution. Depending on the etching parameters, for example, current density, HF concentration, substrate doping type, and level, the physical properties of PS can be varied [11]. Therefore, porous silicon is also particularly suitable in order to study the influence of spatial confinement on fundamental properties of pore condensed matter as a function of pore geometry parameters [12-15]. The conditions for the formation of PS on all types of substrates in terms of current density and HF concentrations were reported by Zhang et al. [16], where they have shown that the formation of PS occurring during anodization was found to be dependent on the nature of electrochemical reactions. Numerous theories on the formation mechanisms of PS have been reported since its discovery. Beale et al. [17, 18], Smith et al. [9, 19], Zhang et al. [16, 20], and Unagami [21] have proposed models to interpret the mechanisms responsible for producing porous silicon. Even though the mechanisms were different, almost all the investigators believed that the existence of holes is a prerequisite in proceeding the electrochemical polishing or formation of porous silicon. The discovery of the photoluminescence (PL) of PS by Canham in 1990 [22] has triggered a large-scale investigations on PS materials including their interfaces, structure, temperature dependence, and electroluminescence properties [23-27]. The electroluminescence property of PS was reported by Lehmann and Gösele [28], where they have 
shown that the red color of PS changes to yellow color by increase in applied current density during etching and this change in color was attributed to quantum confinement effect in silicon nanocrystalline between the pores. There are many theoretical evidence that quantum confinement due to nanoscale-sized crystallites of Si results in the occurrence of PL in PS layers [29-32]. Quantum size effects lead to an increase in the band gap of the nanocrystals compared to single-crystal silicon which could explain the visible luminescence properties [33]. To further explore the occurrence of PL in PS, we have systematically studied the quantum confinement effect in three different pore diameter PS samples. In this paper, we report the effect of the composition of etching electrolyte on physical and electronic properties of PS. The systematic studies of different pore diameter PS was carried out by using the Brunnauer-Emmer-Teller model (BET) on nitrogen absorption/desorption isotherm, photoluminescence, scanning electron microscopy, and Raman spectroscopy.

\section{Experimental Details}

PS layers were prepared by electrochemical anodic etching of a highly doped $P$-type $\langle 100\rangle$ oriented silicon substrate with a resistivity of $0.01-0.02 \Omega \mathrm{cm}$. The electrochemical cell was made of Teflon and the base plate was made of aluminum. A silicon wafer was mounted at the base plate by using an $O$-ring that allowed $7.0 \mathrm{~cm}^{2}$ of the $\mathrm{Si}$ surface to be exposed to the electrolytes consisting of three different concentrations of $3: 7,4: 6$, and $6: 4$ by volume 48\% hydrofluoric acid (HF): 98\% ethanol, respectively. Prior to each experiment, the Si wafers were ultrasonically cleaned in propanol and acetone. The etching current density $14.5 \mathrm{~mA} / \mathrm{cm}^{2}$ was applied for 30 minutes. The thicknesses of the porous layers determined with an optical microscope were in the range of $20-25 \mu \mathrm{m}$. The prepared PS was then fixed into the homemade all-metal gas handling system (BET setup) that is equipped with a membrane pressure gauge of 1000 mbar full scale to study the physical properties of PS by measuring adsorption/desorption isotherms of $\mathrm{N}_{2}$ in porous silicon at $77 \mathrm{~K}$. The $\mathrm{PL}$ measurements were done using a Hamamatsu TG-SWNIR, C9405CA spectrometer, and a laser diode exciting the sample at a wavelength of $405 \mathrm{~nm}$. Raman scattering experiments were performed using the excitation line $\lambda=532 \mathrm{~nm}$ of a semiconductor laser in a quasibackscattering geometry. The laser power of $5 \mathrm{~mW}$ was focused to a $0.1 \mathrm{~mm}$ diameter spot on the PS surface. The scattered spectra were collected by a DILOR-XY triple spectrometer and a nitrogen cooled charge-coupled device detector. For the measurements, the samples were placed in a sample chamber which was evacuated or, alternatively, filled with helium gas in order to suppress the low frequency Raman scattering by air and to prevent possible laserinduced oxidation of PS layers. All measurements were carried out at room temperature. The changes in surface morphology of three different PS samples were investigated by using a field emission-type scanning electron microscope (FE-SEM) (SUPRA35, Carl Zeiss NTS GmbH).

\section{Results and Discussion}

During electrochemical etching of silicon, the pore forms in silicon by anodic polarization in aqueous HF solution, depending on the electrode potential and HF concentration. Many theories for pore formation mechanism have been reported in the literature $[9,17-21]$. In general, the porous silicon formation is considered to result from the inhomogeneous dissolution of the silicon surface due to competing reactions: silicon oxide formation followed by dissolution of the oxide versus a direct dissolution of silicon by HF [34]. The illustrative equation of the overall process during the PS formation can be expressed as follows:

$$
\begin{aligned}
& \mathrm{Si}+2 \mathrm{HF}+2 h^{+} \longrightarrow \mathrm{SiF}_{2}+2 \mathrm{H}^{+} \\
& \mathrm{SiF}_{2}+4 \mathrm{HF}^{-} \longrightarrow \mathrm{H}_{2}+\mathrm{H}_{2} \mathrm{SiF}_{6}
\end{aligned}
$$

The etching rate is determined by the holes $\left(h^{+}\right)$accumulation in the adjacent regions of the $\mathrm{HF}$ electrolyte and $\mathrm{Si}$ atoms.

The porous silicon was formed in homogeneously mixed electrolyte composed of $3: 7,4: 6$ and $6: 4$ by volume $48 \%$ hydrofluoric acid: $98 \%$ ethanol with constant applied etching current density of $14.5 \mathrm{~mA} / \mathrm{cm}^{2}$ for 30 minutes. The mesoporous silicon prepared with different concentrations of HF was characterized by nitrogen sorption isotherms, field emission-type scanning electron microscope, photoluminescence spectroscopy, and Raman spectroscopy.

3.1. Physical Properties of Porous Silicon. The physical properties of sample (a) (prepared in electrolyte composition of $30 \%$ of $\mathrm{HF}$ and $70 \%$ of ethanol by volume, i.e., 3 : 7 ), sample (b) (prepared in electrolyte composition of $40 \%$ of $\mathrm{HF}$ and $60 \%$ of ethanol by volume, i.e., $4: 6$ ) and sample (c) (prepared in electrolyte composition of $60 \%$ of $\mathrm{HF}$ and $40 \%$ of ethanol by volume, i.e., $6: 4$ ) were investigated by measuring of nitrogen adsorption/desorption isotherm at $77 \mathrm{~K}$. Figure 1 shows the nitrogen sorption isotherm for the all three samples. In Figure 1 we plot the filling fraction $f=N / N_{0}$, where $N$ refers to the number of adsorbed $\mathrm{N}_{2}$ molecules and $N_{0}$ to the number of particles necessary for a complete filling of the porous layer, versus the reduced vapor pressure $P_{r}=P / P_{0}$, where $P_{0}$ represents the bulk vapor pressure of nitrogen at $77 \mathrm{~K}$ and $P$ the vapor pressure as measured with a capacitive pressure gauge of 1000 mbar full scale after each adsorption step. In Figures 1(a) and 1(b) three regions can be identified to study the physical properties of these samples. The first step, that is, reversible multilayer growth on the pore walls at small-reduced pressures gives access to the specific surface of the porous host (surface per pore volume) via a generalization of the Langmuir monolayer growth model towards heterogeneous adsorption of multilayers, established by Brunauer et al. (BET model) [35]. The second part is a hysteretic region between adsorption and desorption branch where the pores are filled by a capillary condensation process. The hysteresis between adsorption and desorption branches is also typical for capillary condensation. The third part, that is, plateau indicates the complete filling of the pores, and the 


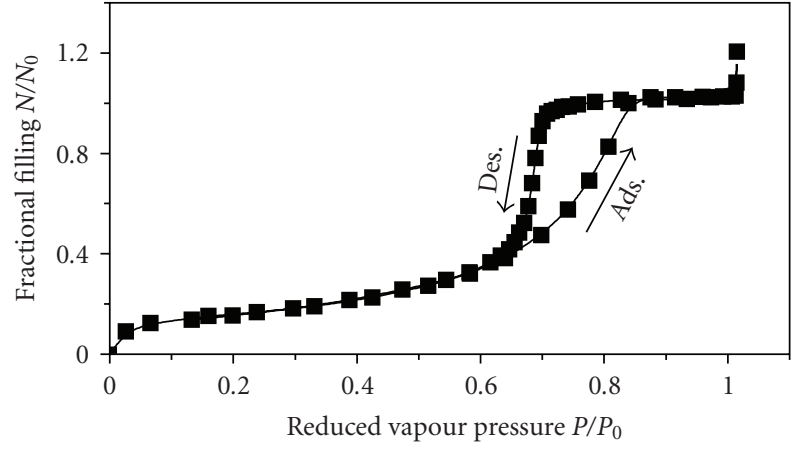

(a)

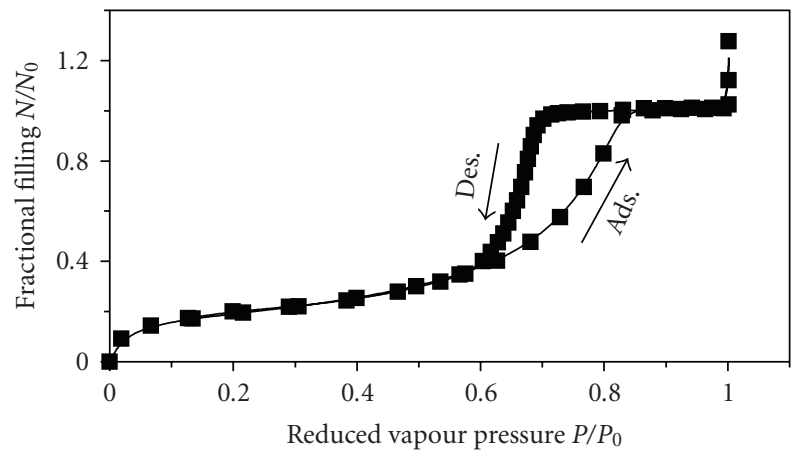

(b)

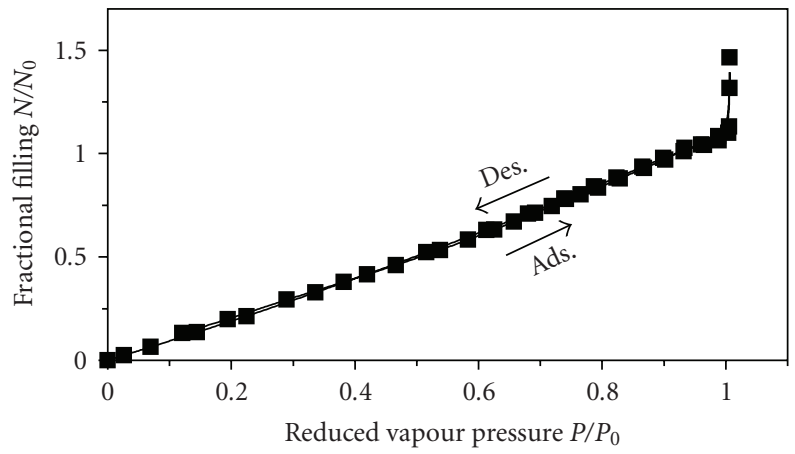

(c)

FIGURE 1: Adsorption (ads.) \desorption (des.) isotherms of $\mathrm{N}_{2}$ at $77 \mathrm{~K}$ in PS for the sample (a) (prepared with $3: 7 \Leftrightarrow \mathrm{HF}:$ ethanol), sample (b) (prepared with $4: 6 \Leftrightarrow \mathrm{HF}$ : ethanol) and sample (c) (prepared with $6: 4 \Leftrightarrow \mathrm{HF}:$ ethanol).

amount of liquid corresponding to the volume of the gas adsorbed allows the determination of porosity. The surface area and pore diameter were determined by using the BET equation given as follows:

$$
\frac{P / P_{0}}{v\left(1-P / P_{0}\right)}=\frac{1}{v_{m} c}+\frac{c-1}{v_{m} c} \frac{P}{P_{0}}
$$

where $v$ is the amount adsorbed at pressure $P, P_{0}$ is the saturation pressure, $v_{m}$ is the amount adsorbed in a monolayer, and $c$ is a constant related to the molar heat of adsorption of the first layer.

Equation (2) has been used in gas sorption isotherms in porous matrix to determine the $v_{m}$ and $c$ from the

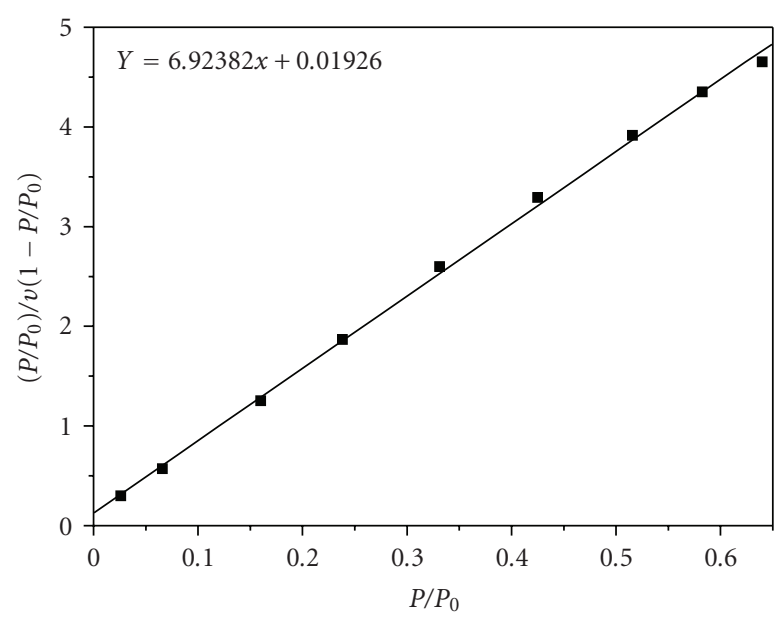

- Experimental results - BET fit

(a)

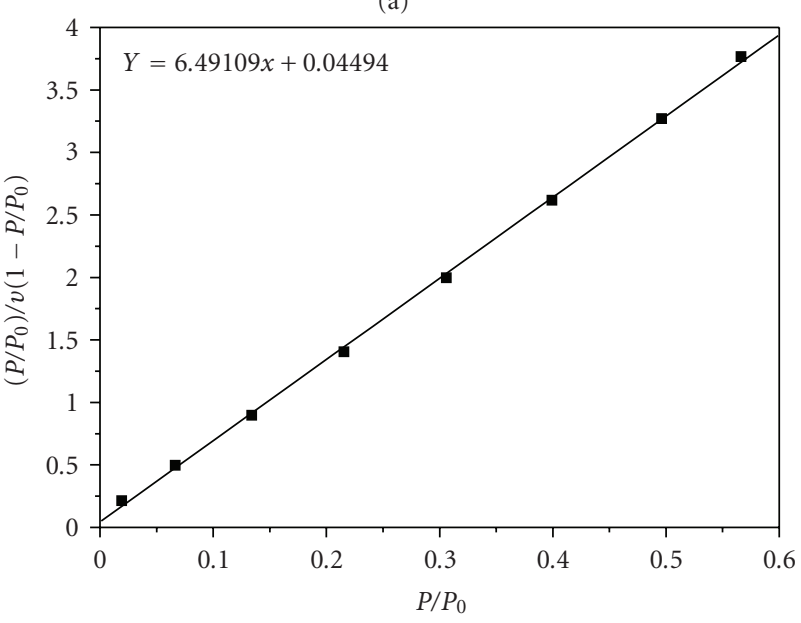

- Experimental results - BET fit

(b)

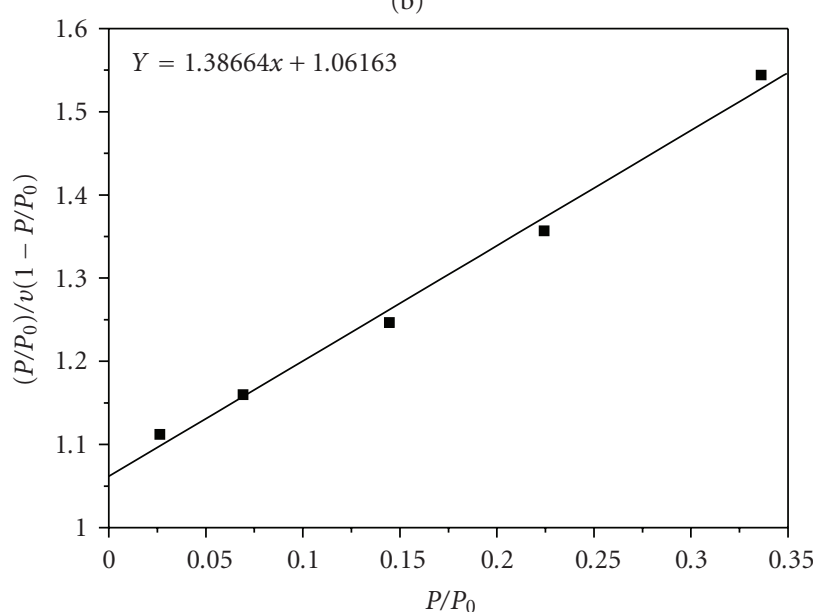

- Experimental results

— BET fit

(c)

FIGURE 2: BET plots of sorption isotherm of samples (a), (b), and (c). 


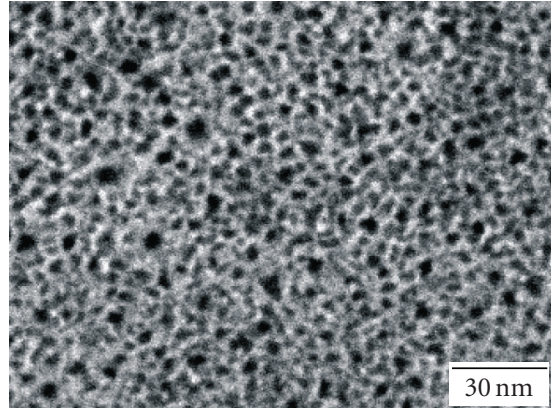

(a)

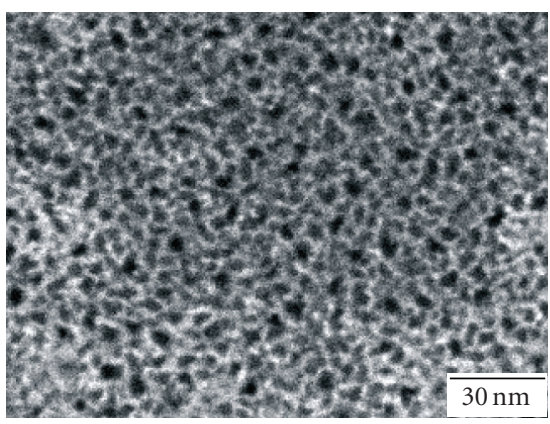

(b)

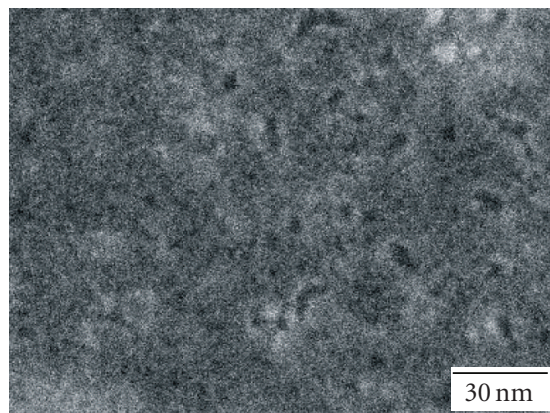

(c)

Figure 3: FE-SEM plan views of sample (a), (b), and (c).

slope and the intercept of the straight line obtained from a plot of $\left(P / P_{0}\right) / v\left(1-P / P_{0}\right)$ as a function of $P / P_{0}$ shown in Figures $2(\mathrm{a})-2(\mathrm{c})$. The pore diameter, porosity, and specific surface area of sample (a), (b), and (c) calculated from the nitrogen isotherm shown in Figure 1 by using BET analysis shown in Figure 2 are listed in Table 1. The pore diameter and porosity of mesoporous silicon were found to decrease with an increase of the HF concentration in the used etching electrolyte at constant applied current density. The theoretical and experimental details concerning decrease of pore diameter and porosity with increase of HF concentration in etching electrolyte have been reported by many researchers $[16,20]$. In sample (c), which has a pore diameter of $3 \mathrm{~nm}$, the hysteresis was not found as shown in Figure 1(c) indicating that the very small-pores are not filled by capillary condensations. The behavior of the sample (c) isotherm may be understood in terms of a simple model; during multilayer adsorption at pore walls the pores become

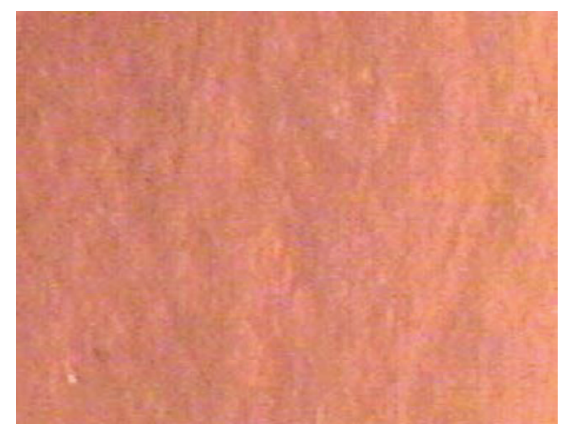

(a)

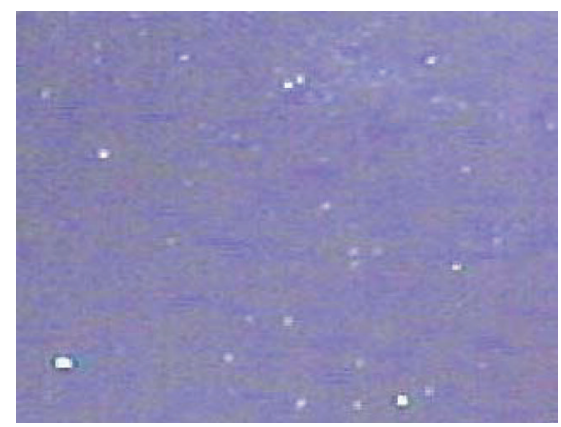

(b)

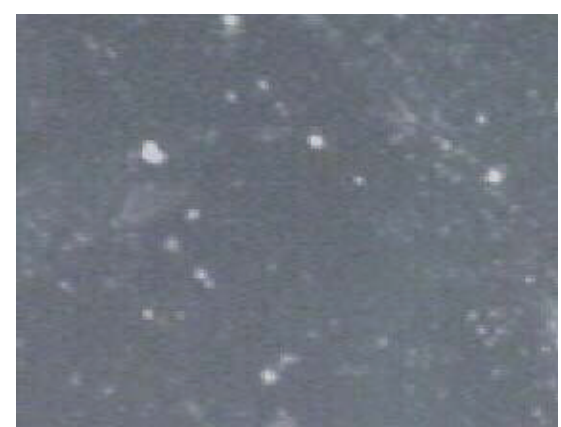

(c)

FIGURE 4: Visual color observation of samples (a), (b), and (c).

filled by a meeting of the adsorbed films from opposing walls as also reported in literature [36].

These observations were also supported by scanning electron microscopy. An FE-SEM was utilized to study the surface morphology of sample (a), (b), and (c). The pores in sample (a) are clearly observed, as shown in Figure 3(a). The pore diameter in sample (a), as obtained from Figure 3(a), was in the range of $8-12 \mathrm{~nm}$. The pore diameter in sample (b) as obtained from Figure 3(b) was found in the range of $6-10 \mathrm{~nm}$ while in sample (c) as shown in Figure 3(c), the pore diameter is not so clear but could be expected in the range of $2-4 \mathrm{~nm}$. Since it is difficult to have good contrast for very small-pores by microscopy techniques therefore the aforementioned BET technique has been frequently used to study such a small-pore matrix. The pore diameters obtained from SEM are in agreement with the values obtained from nitrogen sorption isotherms. 
TABLE 1: Variation of physical properties, shift, and broadening in phonon peak of samples (a), (b), and (c).

\begin{tabular}{|c|c|c|c|c|c|c|}
\hline $\begin{array}{l}\text { Sample } \\
\text { details }\end{array}$ & $\begin{array}{c}\text { Electrolyte } \\
\text { (HF : ethanol) }\end{array}$ & Pore dia. $(\mathrm{nm})$ & Porosity \% & $\begin{array}{l}\text { Specific surface } \\
\text { area }\left(\mathrm{m}^{2} / \mathrm{cm}^{3}\right)\end{array}$ & $\begin{array}{c}\text { Raman } \\
\text { shift } \mathrm{cm}^{-1}\end{array}$ & Peak width $\mathrm{cm}^{-1}$ \\
\hline (a) & $3: 7$ & 10 & 54 & 406 & 516 & 8.3 \\
\hline (b) & $4: 6$ & 8 & 45 & 433 & 518 & 4.9 \\
\hline (c) & $6: 4$ & 3 & 30 & 900 & 519 & 4.2 \\
\hline
\end{tabular}

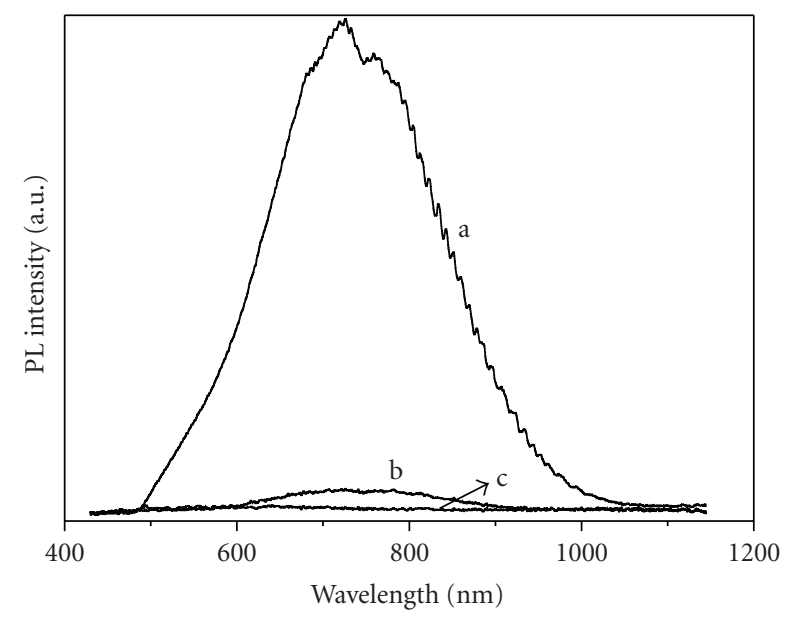

c: pore diameter $3 \mathrm{~nm}$ b: pore diameter $8 \mathrm{~nm}$ a: pore diameter $10 \mathrm{~nm}$

FIgURE 5: Photoluminescence spectra of samples (a), (b), and (c).

3.2. Visual Color Observations and Photoluminescence Study. In Figures 4(a)-4(c) we show the color observation of samples (a), (b), and (c): sample (a) shows the red color in transmission mode, sample (b) violet color, and sample (c) is of grey color and opaque in transmission mode. With changing the pore diameter from $3 \mathrm{~nm}$ to $10 \mathrm{~nm}$ the color of porous silicon changes from grey to red. The different color of porous silicon due to pore diameter was also reported by Lehmann and Gösele [28], where they have shown that with increase in pore diameter, that is, decrease in silicon region between the pores results the shift of red color to yellow. These observations are also supported by our photoluminescence measurements. Photoluminescence is directly related to the electronic structure and transitions. Differences in the electronic behavior between bulk and low-dimensional semiconductors arise due to the difference in the electron density of states, $g(E)$. For example, $g(E)$ of a bulk semiconductor has a continuous dependence $g(E) \sim E^{1 / 2}$, whereas in two-dimensional semiconductors it has a step-like dependence on energy. In one-dimensional semiconductor structures it diverges as $E^{-1 / 2}$ and for zerodimensional semiconductor it is a delta function of energy. The characteristic change of the band gap with decrease in size of the nanostructures can be studied using by the observation of the blue shift in the photoluminescence peak position [37]. Thus, photoluminescence is useful in the study of quantum confinement of electrons in lowdimensional materials $[38,39]$. In Figures $5(a)-5$ (c) we show the PL spectra of samples (a), (b), and (c). It can be seen from Figure 5 that sample (c) which has a pore diameter in the range of $3 \mathrm{~nm}$ does not show any PL peak. With an increase of the pore diameter however, the PL signal starts to appear. In Figure $5(\mathrm{~b})$ we can see a small intensity of PL peak while in sample (a) as shown in Figure 5(a) we see a strong PL peak around at $735 \mathrm{~nm}$. Bulk silicon has an indirect band gap and does not show any photoluminescence peak while porous silicon has direct band gap and shows a photoluminescence peak at around $750 \mathrm{~nm}$. Several mechanisms have been suggested to explain the appearance of this luminescence signal, such as defects that localize carriers at extrinsic centers or surface states providing radiative recombination centers, surface hydrides ( $\mathrm{SiH}_{\mathrm{x}}$ groups) or the formation of siloxene (an $\mathrm{Si}-\mathrm{O}-\mathrm{H}$ based polymer), or quantum confinement effects of the excitons caused by their spatial confinement within the Si-nanocrystallites. The latter mechanism was proven to be the origin of the observed luminescence $[40,41]$. The absence of PL from sample (c) indicates that porous silicon with the pore diameter of $3 \mathrm{~nm}$ or less than that behaves as bulk silicon where the silicon crystallites size between two pores are too large to lead to an efficient quantum confinement. The absence of PL signal from sample (c) and a strong signal from sample (a) indicates that the quantum confinement effect in narrow silicon regime between two pores results in strong PL signal.

3.3. Phonon Dynamics in the Si Pore Walls. In order to explain the dramatic increase of the PL signal of the sample (a) compared to sample (b) and (c), we have investigated the structural information of the porous layer using Raman spectroscopy. Photoluminescence and Raman spectra of porous silicon give the information of a crosssectional view of silicon nanocrystallites which remains between the pores, through the quantum confinement effect. Raman spectroscopy has extensively been used to study the structural, mechanical, and physical properties of PS [42]. It is an emission technique that involves inelastic scattering of incident laser photons with crystal or molecular vibrations and results in spectral peaks that are shifted from the incident light. PS is composed of wires or dots of nonuniform dimensions. When the size of $\mathrm{c}-\mathrm{Si}$ is reduced to smaller dimensions, the shift and asymmetric broadening in Raman peak is observed. A respective theoretical and experimental analysis of Raman scattering for smaller dimension materials 


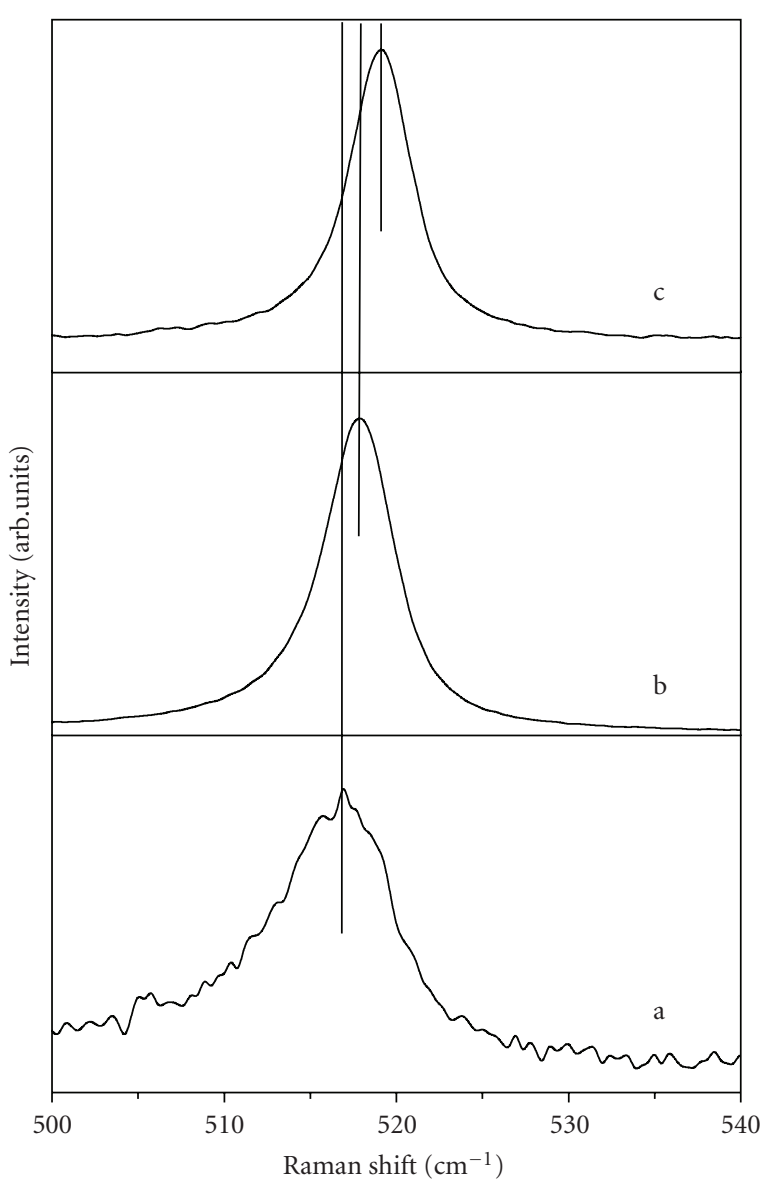

Figure 6: Raman spectra of samples (a), (b), and (c).

can be found in the literature $[43,44]$. In Figure 6 we show the phonon frequency of porous silicon samples (a), (b), and (c). A peak shift was observed from 519 to $516 \mathrm{~cm}^{-1}$ and a broadening of the peak width full width at half maximum (FWHM) from 4.2 (symmetric) to $8.3 \mathrm{~cm}^{-1}$ (asymmetric) with increases in pore diameter from $3 \mathrm{~nm}$ to $10 \mathrm{~nm}$, respectively. The shift of the phonon peak towards lower wave number and broadening of the peak width with increase in pore diameter and porosity is attributed to the confinement of optical phonons in nanodimensional Si crystallites between the pores $[45,46]$. On the basis of physical properties obtained by BET and FE-SEM and information received from photoluminescence and Raman spectroscopy, it is revealed that the appearance of strong PL peak with increase in pore diameter is due to quantum confinement effect. Contributions to PL from any kind of defect, localized state, or chemical bonding are unlikely. Following the discussion above, it could be understood that PS can be used in two ways, first as a porous matrix template like in sample (c) with a small-pore diameter to study embedded guest molecule's confinement effect in PS, second PS itself as an optical material where a type of sample (a) could be utilized to study the optical properties of PS.

\section{Conclusions}

By a combination of volumetric sorption isotherms, visual color observation, photoluminescence, scanning electron microscopy, and Raman spectroscopy, we studied the effect of HF concentration on physical and electronic properties of porous silicon. It was found that porous silicon with pore diameter of $3 \mathrm{~nm}$ or smaller does not show any photoluminescence while pore diameter of $10 \mathrm{~nm}$ shows a PL peak of large intensity. From this we can conclude that the porous silicon is not only a potential candidate for new silicon-based optoelectronic devices but it also enables the study of the electronic interaction on a nanometer scale caused by quantum confinement effects.

\section{Acknowledgment}

The authors acknowledge financial support by the German Research Foundation (DFG).

\section{References}

[1] O. K. Andersen and E. Veje, "Experimental study of the energy-band structure of porous silicon," Physical Review B, vol. 53, no. 23, pp. 15643-15652, 1996.

[2] P. G. Abramof, A. F. Beloto, A. Y. Ueta, and N. G. Ferreira, "X-ray investigation of nanostructured stain-etched porous silicon," Journal of Applied Physics, vol. 99, no. 2, Article ID 024304, 5 pages, 2006.

[3] D. Wallacher, N. Künzner, D. Kovalev, N. Knorr, and K. Knorr, "Capillary condensation in linear mesopores of different shape," Physical Review Letters, vol. 92, no. 19, Article ID 195704, 4 pages, 2004.

[4] K. D. Hirschman, L. Tsybeskov, S. P. Duttagupta, and P. M. Fauchet, "Silicon-based visible light-emitting devices integrated into microelectronic circuits," Nature, vol. 384, no. 6607, pp. 338-341, 1996.

[5] C. C. Striemer, T. R. Gaborski, J. L. McGrath, and P. M. Fauchet, "Charge- and size-based separation of macromolecules using ultrathin silicon membranes," Nature, vol. 445, no. 7129, pp. 749-753, 2007.

[6] V. S.-Y. Lin, K. Motesharei, K.-P. S. Dancil, M. J. Sailor, and M. R. Ghadiri, "A porous silicon-based optical interferometric biosensor," Science, vol. 278, no. 5339, pp. 840-843, 1997.

[7] P. Kumar and P. Huber, "Nucleation and growth of copper on mesoporous silicon by immersion plating," Journal of Physics D: Applied Physics, vol. 40, no. 9, pp. 2864-2869, 2007.

[8] H. Föll, J. Carstensen, and S. Frey, "Porous and nanoporous semiconductors and emerging applications," Journal of Nanomaterials, vol. 2006, Article ID 91635, 10 pages, 2006.

[9] R. L. Smith and S. D. Collins, "Porous silicon formation mechanisms," Journal of Applied Physics, vol. 71, no. 8, pp. R1R22, 1992.

[10] H. Liu and Z. L. Wang, "Etching silicon wafer without hydrofluoric acid," Applied Physics Letters, vol. 87, no. 26, Article ID 261913, 3 pages, 2005.

[11] R. Herino, G. Bomchil, K. Barla, C. Bertrand, and J. L. Ginoux, "Porosity and pore size distributions of porous silicon layers," Journal of the Electrochemical Society, vol. 134, no. 8, pp. 19942000, 1987.

[12] P. Kumar, T. Hofmann, K. Knorr, P. Huber, P. Scheib, and P. Lemmens, "Tuning the pore wall morphology of mesoporous 
silicon from branchy to smooth, tubular by chemical treatment," Journal of Applied Physics, vol. 103, no. 2, Article ID 024303, 6 pages, 2008.

[13] R. Guégan, D. Morineau, C. Loverdo, W. Béziel, and M. Guendouz, "Evidence of anisotropic quenched disorder effects on a smectic liquid crystal confined in porous silicon," Physical Review E, vol. 73, no. 1, Article ID 011707, 6 pages, 2006.

[14] A. Henschel, T. Hofmann, P. Huber, and K. Knorr, "Preferred orientations and stability of medium length $n$-alkanes solidified in mesoporous silicon," Physical Review E, vol. 75, no. 2, Article ID 021607, 9 pages, 2007.

[15] A. Khokhlov, R. Valiullin, J. Kärger, F. Steinbach, and A. Feldhoff, "Freezing and melting transitions of liquids in mesopores with ink-bottle geometry," New Journal of Physics, vol. 9, no. 8, pp. 272-281, 2007.

[16] X. G. Zhang, S. D. Collins, and R. L. Smith, "Porous silicon formation and electropolishing of silicon by anodic polarization in HF solution," Journal of the Electrochemical Society, vol. 136, no. 5, pp. 1561-1565, 1989.

[17] M. I. J. Beale, N. G. Chew, M. J. Uren, A. G. Cullis, and J. D. Benjamin, "Microstructure and formation mechanism of porous silicon," Applied Physics Letters, vol. 46, no. 1, pp. 8688, 1985.

[18] M. I. J. Beale, J. D. Benjamin, M. J. Uren, N. G. Chew, and A. G. Cullis, "An experimental and theoretical study of the formation and microstructure of porous silicon," Journal of Crystal Growth, vol. 73, no. 3, pp. 622-636, 1985.

[19] R. L. Smith, S.-F. Chuang, and S. D. Collins, "A theoretical model of the formation morphologies of porous silicon," Journal of Electronic Materials, vol. 17, no. 6, pp. 533-541, 1988.

[20] X. G. Zhang, "Mechanism of pore formation on n-type silicon," Journal of the Electrochemical Society, vol. 138, no. 12, pp. 3750-3756, 1991.

[21] T. Unagami, "Formation mechanism of porous silicon layer by anodization in HF solution," Journal of the Electrochemical Society, vol. 127, no. 2, pp. 476-483, 1980.

[22] L. T. Canham, "Silicon quantum wire array fabrication by electrochemical and chemical dissolution of wafers," Applied Physics Letters, vol. 57, no. 10, pp. 1046-1048, 1990.

[23] M. L. Ciurea, M. Drãghici, S. Lazanu, et al., "Trapping levels in nanocrystalline porous silicon," Applied Physics Letters, vol. 76, no. 21, pp. 3067-3069, 2000.

[24] A. Kanjilal, M. Song, K. Furuya, and B. Mallik, "Structural property of nanoporous silicon: evidence of near ultraviolet photoluminescence," Journal of Physics D, vol. 40, no. 17, pp. 5044-5049, 2007.

[25] O. Teschke, "Visualization of nanostructured porous silicon by a combination of transmission electron microscopy and atomic force microscopy," Applied Physics Letters, vol. 68, no. 15, pp. 2129-2131, 1996.

[26] C. H. Perry, F. Lu, F. Namavar, N. M. Kalkhoran, and R. A. Soref, "Photoluminescence spectra from porous silicon (111) microstructures: temperature and magnetic-field effects," Applied Physics Letters, vol. 60, no. 25, pp. 3117-3119, 1992.

[27] A. Halimaoui, C. Oules, G. Bomchil, et al., "Electroluminescence in the visible range during anodic oxidation of porous silicon films," Applied Physics Letters, vol. 59, no. 3, pp. 304306, 1991.

[28] V. Lehmann and U. Gösele, "Porous silicon: quantum sponge structures grown via a self-adjusting etching process," Advanced Materials, vol. 4, no. 2, pp. 114-116, 1992.
[29] L. Ferraioli, M. Wang, G. Pucker, et al., "Photoluminescence of silicon nanocrystals in silicon oxide," Journal of Nanomaterials, vol. 2007, Article ID 43491, 5 pages, 2007.

[30] R. Behrensmeier, F. Namavar, G. B. Amisola, F. A. Otter, and J. M. Galligan, "Further evidence for quantum confinement in porous silicon," Applied Physics Letters, vol. 62, no. 19, pp. 2408-2410, 1993.

[31] T. van Buuren, Y. Gao, T. Tiedje, J. R. Dahn, and B. M. Way, "Evidence for quantum confinement in porous silicon from soft X-ray absorption,” Applied Physics Letters, vol. 60, no. 24, pp. 3013-3015, 1992.

[32] M. Voos, Ph. Uzan, C. Delalande, G. Bastard, and A. Halimaoui, "Visible photoluminescence from porous silicon: a quantum confinement effect mainly due to holes," Applied Physics Letters, vol. 61, no. 10, pp. 1213-1215, 1992.

[33] D. J. DiMaria, J. R. Kirtley, E. J. Pakulis, et al., "Electroluminescence studies in silicon dioxide films containing tiny silicon islands," Journal of Applied Physics, vol. 56, no. 2, pp. 401-416, 1984.

[34] X. G. Zhang, "Morphology and formation mechanisms of porous silicon," Journal of the Electrochemical Society, vol. 151, no. 1, pp. C69-C80, 2004.

[35] S. Brunauer, P. H. Emmett, and E. Teller, "Adsorption of gases in multimolecular layers," Journal of the American Chemical Society, vol. 60, no. 2, pp. 309-319, 1938.

[36] J. Baumert, B. Asmussen, C. Gutt, and R. Kahn, "Pore-size dependence of the self-diffusion of hexane in silica gels," Journal of Chemical Physics, vol. 116, no. 24, pp. 10869-10876, 2002.

[37] P. Moriarty, "Nanostructured materials," Reports on Progress in Physics, vol. 64, no. 3, pp. 297-381, 2001.

[38] S. Okamoto and Y. Kanemitsu, "Photoluminescence properties of surface-oxidized Ge nanocrystals: surface localization of excitons," Physical Review B, vol. 54, no. 23, pp. 16421-16424, 1996.

[39] A. K. Sood, K. Jayaram, and D. V. S. Muthu, "Raman and high-pressure photoluminescence studies on porous silicon," Journal of Applied Physics, vol. 72, no. 10, pp. 4963-4965, 1992.

[40] A. G. Cullis, L. T. Canham, and P. D. J. Calcott, "The structural and luminescence properties of porous silicon," Journal of Applied Physics, vol. 82, no. 3, pp. 909-965, 1997.

[41] O. Bisi, S. Ossicini, and L. Pavesi, "Porous silicon: a quantum sponge structure for silicon based optoelectronics," Surface Science Reports, vol. 38, no. 1-3, pp. 1-126, 2000.

[42] G. Irmer, "Raman scattering of nanoporous semiconductors," Journal of Raman Spectroscopy, vol. 38, no. 6, pp. 634-646, 2007.

[43] H. Münder, C. Andrzejak, M. G. Berger, et al., "A detailed Raman study of porous silicon," Thin Solid Films, vol. 221, no. 1-2, pp. 27-33, 1992.

[44] H. Richter, Z. P. Wang, and L. Ley, "The one phonon Raman spectrum in microcrystalline silicon," Solid State Communications, vol. 39, no. 5, pp. 625-629, 1981.

[45] I. H. Campbell and P. M. Fauchet, "The effects of microcrystal size and shape on the one phonon Raman spectra of crystalline semiconductors," Solid State Communications, vol. 58, no. 10, pp. 739-741, 1986.

[46] Z. Sui, P. P. Leong, I. P. Herman, G. S. Higashi, and H. Temkin, "Raman analysis of light-emitting porous silicon," Applied Physics Letters, vol. 60, no. 17, pp. 2086-2088, 1992. 

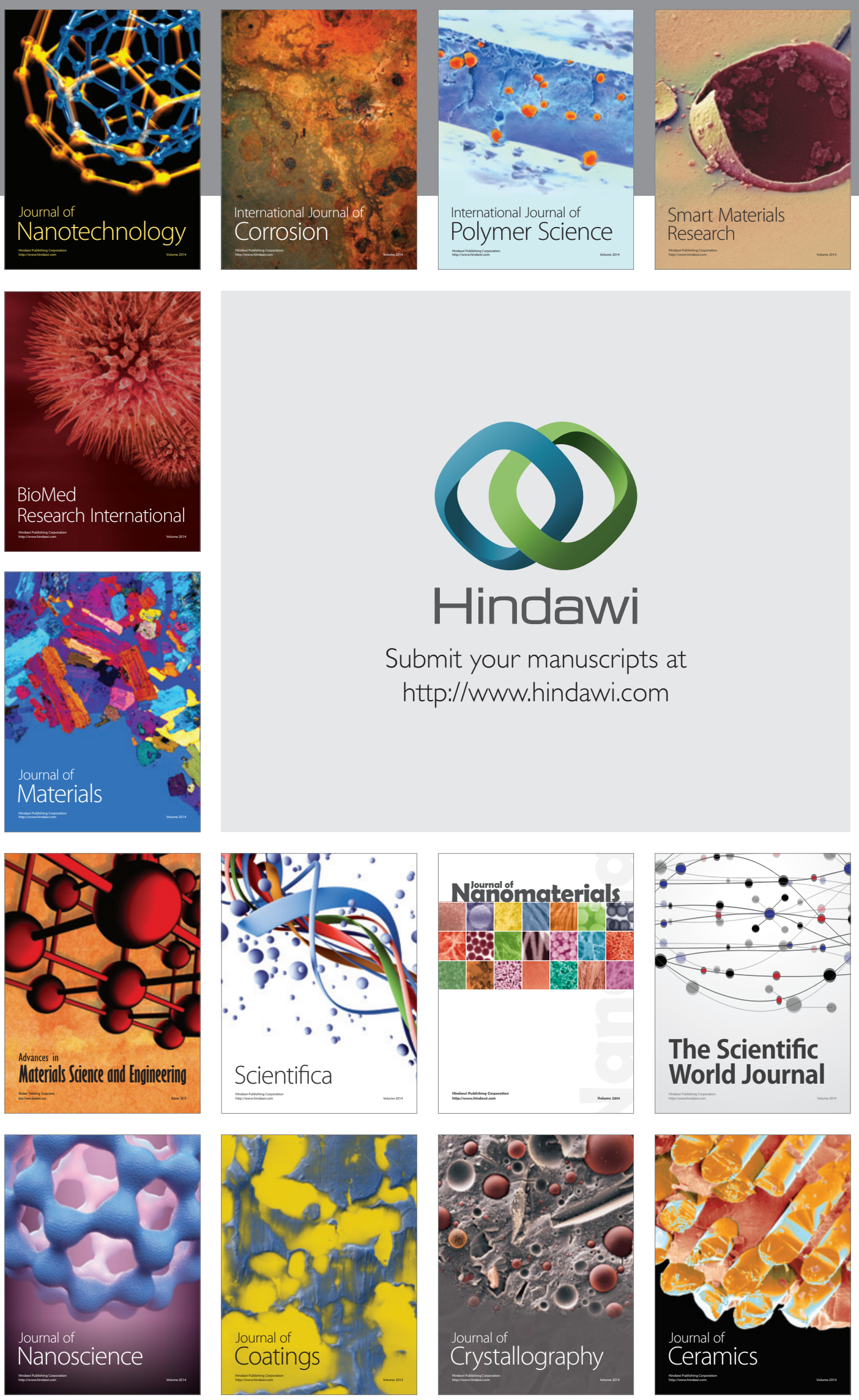

The Scientific World Journal

Submit your manuscripts at

http://www.hindawi.com

\section{World Journal}

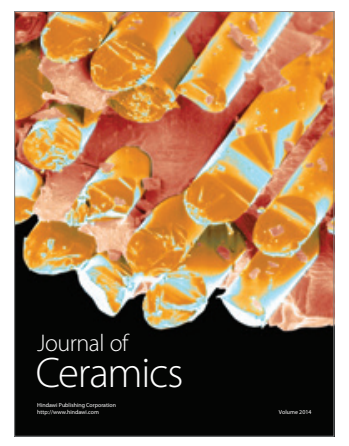

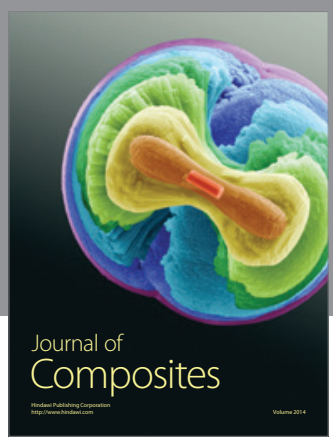
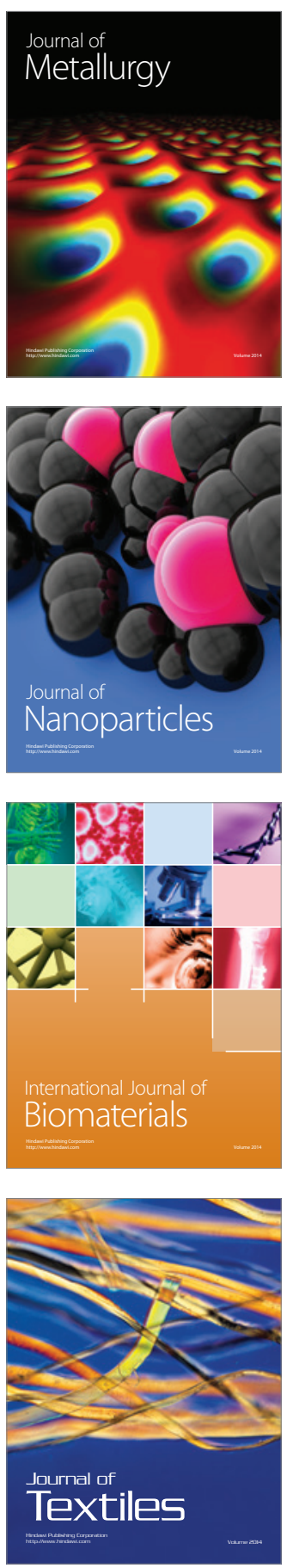